

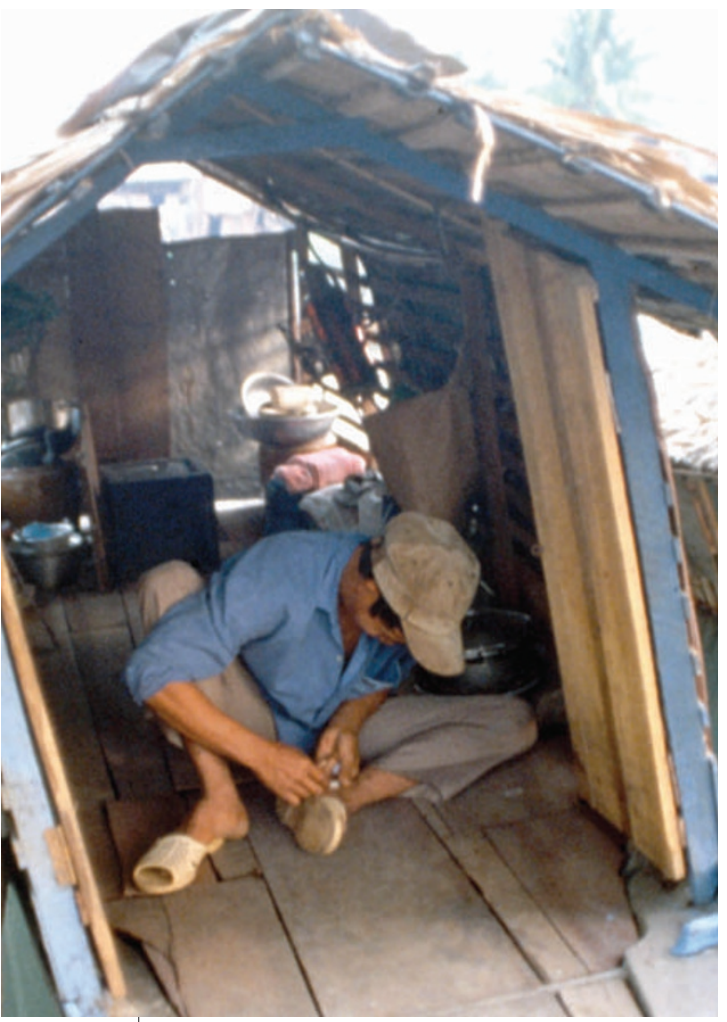

Social pariahs: Vietnamese opium addicts are shunned by society, but it is claimed that a cocktail of herbs has helped some in state-funded rehabilitation (below) to beat their problem.

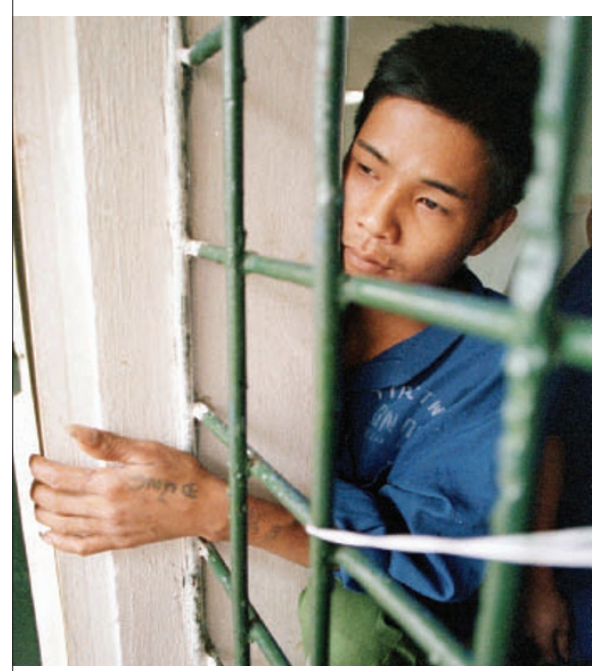

opiates - provided relief from drug withdrawal. "It was dangerous, but there was no other choice," says Dan.

Whether this tale has been embellished is hard to say. But flashy showmanship doesn't seem to be Dan's style. On our trip to Hoa Binh, he is quiet and detached; facts about his work on Heantos have to be coaxed from him through an interpreter.

Perhaps Dan has grown tired of telling the story, given the tortuous road that Heantos has travelled. The treatment first came to international attention in 1997, when the United Nations Development Programme (UNDP) decided to invest US $\$ 400,000$ in its scientific development. Since then, a similar

sum has come from the Norwegian government, with additional support from the United Nations Educational, Scientific and Cultural Organization.

By local standards, this is lavish funding. And it has caused some tensions within Vietnam, where there are competing approaches to drug detoxification. "Heantos has certainly been contentious," says Ayo Wahlberg, a graduate student at the London School of Economics who is interested in the regulation of herbal medicines, and has made several trips to Vietnam. In the late 1990s, for instance, rumours circulated that some patients had died following adverse reactions. But subsequent safety evaluations by the Vietnamese authorities have given Heantos a clean bill of health.

In parallel, Sung and his colleagues have refined the techniques used to produce Heantos, replacing Dan's method of grinding the plants in water with solvent extraction and freeze-drying. They have also begun characterizing the chemical constituents of the resulting formulations. "We have several hundred pure compounds," says Sung. But their identity, and that of the 13 plants from which Heantos is derived, is being kept under wraps until the German patent application is published.

Shortly after the UNDP got involved, there was a flurry of publicity when a group of foreign journalists interviewed Dan and met addicts who had

"If Heantos is shown to have some therapeutic value, it would boost the prospect of a treatment that seems for the past few years to have become stuck in limbo."

been treated with Heantos. Some of the resulting articles painted Heantos as a miracle cure, citing positive results from Vietnamese trials — including a study of 110 veterans of what is known here as the American War, who had become addicted to the morphine used to ease the pain of their wounds.

\section{Outside influence}

But the Vietnamese clinical studies of Heantos have all failed to meet the gold standard of double blind, placebo-controlled trials. Clinical research is weak in Vietnam. So if the effectiveness of Heantos was to be assessed to internationally recognized standards, it seemed that this would require a trial outside Vietnam.

Initially, this was going to be carried out by a team led by Donald Jasinski at the Johns Hopkins School of Medicine in Baltimore, Maryland. But the planned trial's US proponents failed to secure funding. Eventually, the government of the state of North Rhine Westphalia in Germany, where attitudes to herbal medicine are more positive than in many other Western countries, came to the rescue. In 2001, it agreed to fund a trial to test the ability of Heantos to ease withdrawal symptoms.

The protocol, designed by psychiatrist Norbert Scherbaum of the University Hospital in Essen, calls for the treatment to be given to 30 heroin addicts, while another 30 are given a placebo. But before the trial could go ahead, the German authorities demanded analysis of the Heantos formulations by the Institute of Plant Biochemistry in Halle.

Given that Heantos is such a complex mixture, satisfying the demands of regulatory authorities has been a persistent problem, says Wahlberg. Even a 2004 European Union (EU) directive, designed to lower the hurdles for certain herbal remedies, doesn't provide much assistance. It offers a simplified registration procedure, with few requirements for lengthy preclinical tests and clinical trials, for products that have "a well-established medicinal use" within the EU. Heantos is the product of Dan's invention and Sung's chemical expertise, so it doesn't qualify.

Scherbaum hopes to begin enrolling patients in the trial within the next few months, and to have results by the end of this year. Experts who have followed the progress of Heantos are taking a cautious view. "I've seen a lot of 'magic bullets' come and go," says Gabrielle Welle-Strand of the Centre for Medication-Assisted Rehabilitation in Oslo, Norway, who was a member of an international team of addiction specialists that visited Vietnam in 1999 to witness the treatment's use.

Scherbaum's trial also isn't designed to test the claims that Heantos can reduce the underlying craving for drugs that prevents many reformed addicts from keeping clean in the long term. Here, there is no such thing as a miracle cure - as Tung can testify. After his first spell in rehab, aided by Heantos, he returned to his hometown of Mai Chau, in the mountains near the border with Laos. Unable to find work, Tung soon fell in with his old drug-taking friends, and was enslaved to opium once more.

But if Heantos is shown by Scherbaum's trial to have some therapeutic value, it would provide a boost to the prospect of a treatment that seems for the past few years to have become stuck in limbo. Even the Vietnamese authorities have yet to decide whether to approve Heantos for general use.

There's certainly a growing demand in this part of the world for treatments to aid drug rehabilitation. A few years back, Vietnamese drug addicts were few in number, and mostly rural users of opium. Today, there's a burgeoning heroin problem, both in the rapidly expanding cities and along the roads from Laos, used to transport the drug for illegal export.

This trade blights the region, and the wider world. Will Dan and Sung's efforts one day allow Vietnam to be known for exporting an antidote to addiction, rather than merely being a trade route for the criminals who feed it? The answer may lie in Essen.

Peter Aldhous is Nature's chief news \& features editor. 